Original article

\title{
COMPARISON BETWEEN THE EFFECT OF SILYMARIN AND SILVER SULFADIAZINE ON BURNED WOUND HEALING IN RATS
}

\author{
A. ALIABADI \& V. VALADAAN \\ Department of Clinical Studies of School of Veterinary Medicine, \\ Kazerun Branch, Islamic Azad University, Kazerun, Iran
}

\section{Summary}

Aliabadi A. \& V. Valadaan, 2016. Comparison between the effect of silymarin and silver sulfadiazine on burned wound healing in rats. Bulg. J. Vet. Med., 19, No 3, 224-232.

\begin{abstract}
A burn is an injury caused by transfer of thermal energy into tissue resulting in disruption of its normal anatomical structure. An experiment was carried out to compare the effect of silymarin and silver sulfadiazine on burned wound healing in rat. In this study, 36 Wistar rats were divided into 6 groups. A burn was generated on the backs of all rats by brass probe. The burned areas in the first group (control) did not receive any medication, the second group received oral silymarin. Wound areas in third, fourth and fifth group were covered daily with $5 \%, 10 \%$ and $20 \%$ silymarin ointment. Silver sulfadiazine was applied as daily topical treatment of burned wound in the sixth group. At post injury days $0,5,7,14$ and 21, rats from each group were selected, sacrificed and burned skin tissue samples were collected for histopathological examination. Ulceration, acute inflammation, chronic inflammation, crust formation and granulation tissue formation were assessed. The result of this study showed that the use of $10 \%$ silymarin significantly enhanced the burn wound healing process as compared to silver sulfadiazine and other silymarin concentrations.
\end{abstract}

Key words: burn, rat, silver sulfadiazine, silymarin

\section{INTRODUCTION}

Millions of cases of skin burns are recorded around the world each year. It is estimated that burns cause approximately 265,000 deaths annually (Mogosanu et al., 2012). Taking into account the extent and depth of the lesions, the suffering is more or less severe but the complications of burns represent one of the most difficult pathologies (Forjuoh, 2006; Jeschke et al., 2007). Burns are injuries of skin or other tissue caused by heat, radiation, chemical, or electrical contact. Burns cause protein denaturation and thus coagulative necrosis. Around the coagulated tissue, platelets aggregate, vessels constrict, and marginally perfused tissue (known as the zone of stasis) can extend around the injury. In the zone of stasis, tissue is hyperaemic and inflamed. A great deal of research indicated that lipid peroxidation is increased following burn, leading to oxidative destruction of cellular membranes and cell 
death (Sandre et al., 2006; Toklu et al., 2006).

Damage to the normal epidermal barrier allows also bacterial invasion and external fluid loss; damaged tissues often become oedematous, further enhancing volume loss. Heat loss can be significant because thermoregulation of the damaged dermis is absent, particularly in wounds that are exposed (Mogosanu et al., 2012).

Silver sulfadiazine is used to treat or prevent infections on areas of burned skin. It is a topical (for the skin) antibiotic available in generic form. Silver sulfadiazine, although effective, causes some systemic complications such as neutropenia, erythema sultiforme, crystalluria and methaemoglobinemia (Gracia, 2001; Gregory, 2002).

In recent decades plant products have gained a special attention. Many scientists have already focused on crude plant extracts as potential wound healing agents. The effects of plants originate from their ingredients that belong to the various chemical families such as alkaloids, essential oils, flavonoids, tannins, terpenoids, saponins, and phenolic compounds ( $\mathrm{Ru}-$ pesh et al., 2011). These bioactive agents usually modulate one or more phases of the healing process. Flavonoids are naturally occurring substances that possess various pharmacological actions and therapeutic applications.

Silymarin, a flavonoid obtained from Silybum marianum (L.) Gaertn. (milk thistle plant), has been used for centuries to treat liver, spleen and gallbladder disorders. Silymarin possesses strong antioxidant, anti-inflammatory and anticancer activities and also modulates many molecular changes caused by xenobiotics and ultraviolet radiation to protect the skin (Katiyar, 2006; Meeran et al., 2006). Silymarin has also been shown shown to pos- sess antioxidant properties in diabetic wound healing in rats (Aliabadi et al., 2011). Although silymarin is effective against burn-induced oxidative damage in rat skin (Toklu et al., 2007), there is no information about its effect on burned wound healing in comparison with other commercial anti burn products such as silver sulfadiazine. The aim of this study was to compare the effect of silymarin and silver sulfadiazine on burned wound healing in rat.

\section{MATERIALS AND METHODS}

\section{Animals}

This study was performed on thirty-six adult male Wistar rats weighing 150-180 g. Rats were housed in individual cages in the animal laboratory. They were maintained in a $12 \mathrm{~h}$ light, $12 \mathrm{~h}$ dark cycle at room temperature $\left(25 \pm 3{ }^{\circ} \mathrm{C}\right)$ and were fed a standard rat chow for 1 week to be acclimatised prior to the investigation.

\section{Experimental design}

The animals were anaesthetised with intraperitoneal injection of $12.5 \mathrm{mg} / \mathrm{kg} \mathrm{xy}-$ lazine and $70 \mathrm{mg} / \mathrm{kg}$ ketamine hydrochloride (Alfasan, Woerden, Holand). Their backs were shaved and prepared for aseptic procedure. Then a brass probe (heated to $100{ }^{\circ} \mathrm{C}$ ) was placed on each animal's back skin for $1 \mathrm{~s}$ in order to create a $2.0 \mathrm{~cm}^{2}$ second-degree burn injury. All procedures were performed under sterile conditions. No extra local or systemic chemotherapeutic agents were given. Animal showing signs of infection were excluded from the study. A total of 36 rats were randomly divided into six groups of equal number. Group one was control and did not receive any treatment. The second group received oral silymarin (Sigma- 
Aldrich, Germany) $250 \mathrm{mg} / \mathrm{kg} /$ day with gavage needle. Wounded area was covered with 5,10 and $20 \%(30 \mathrm{mg} / \mathrm{kg})$ topical silymarin ointment (Goldar Pharmaceutical Lab, Iran) once daily in groups 3, 4 and 5 respectively. Group six was also treated topically with equal volume of silver sulfadiazine ointment once daily.

Treatment period was 21 days in all groups. Rats from each group were selected and sacrificed randomly on post operation days $0,5,7,14$ and 21 by direct injection of an overdose sodium thiopental $10 \%$ into the animal heart. Wounds diameter were measured and recorded on different days in all groups.

\section{Histopathological examination}

The wounds were excised together with the surrounding skin for histopathological examination. The tissue samples were fixed in $10 \%$ neutral buffered formalin solution for 21 days, embedded in paraffin wax, cut into $5 \mu \mathrm{m}$ thick sections and stained with hematoxylin-eosin and Masson's trichrome stain for examination by light microscopy (Aliabadi et al., 2011). Ulceration, acute inflammation, chronic inflammation and crust formation were graded as: $1+$ (scant), $2+$ (moderate), and $3+$ (abundant). Granulation tissue formation was also graded as: 1+ (partial),
$2+$ (complete, but immature or thin), and $3+$ (complete and mature) (Abramov et al., 2007).

\section{Statistical analysis}

All data are expressed as mean \pm SEM. Wound diameters in different groups were compared with one-way ANOVA, while histological data were analysed with Kruskal-Wallis multivariate analysis followed by Mann-Whitney $U$ test (nonparametric methods). Values of $\mathrm{P}<0.05$ were considered as significant.

\section{RESULTS}

\section{Morphological findings}

In this study Silymarin obtained from Silybum marianum (L.) Gaertn showed significant effect on wound healing processes in rat burned skin. The wound diameters on days 5, 7, 14 and 21 in all groups are reported in Table 1.

On day 5 , the minimum wound diameters were determined (in ascending order) in the sixth, fifth, second, third and fourth groups whereas the maximum wound diameter was determined in the first group (control). Wound diameter on day 7 in the fifth group was smaller compared to the other groups. The average diameter of the

Table 1. Comparison of burned wound diameter $(\mathrm{mm})$ between experimental groups at days 5, 7, 14 and 21 of study. Data are presented as mean $\pm \operatorname{SEM}(n=6)$

\begin{tabular}{lcccc}
\hline Groups & Day 5 & Day 7 & Day 14 & Day 21 \\
\hline 1: Control group & $28.0 \pm 1$ & $25 \pm 1$ & $13 \pm 1$ & $5 \pm 1$ \\
2: Oral silymarin & $25.4 \pm 1$ & $23 \pm 1$ & $15 \pm 5$ & $8 \pm 1$ \\
3: Silymarin 5\% & $25.5 \pm 1$ & $22 \pm 1$ & $8 \pm 1$ & $1 \pm 1^{*}$ \\
4: Silymarin 10\% & $25.5 \pm 1$ & $22 \pm 1$ & $3 \pm 1^{* \mathrm{a}}$ & $\mathrm{N} / \mathrm{A}^{\text {*a }}$ \\
5: Silymarin 20\% & $24.0 \pm 1$ & $21 \pm 1$ & $3 \pm 1^{* \mathrm{a}}$ & $1 \pm 1^{* \mathrm{a}}$ \\
6: Silver sulfadiazine & $23.0 \pm 1$ & $23 \pm 1$ & $8 \pm 1^{*}$ & $6 \pm 1^{*}$ \\
\hline
\end{tabular}

${ }^{*}$ Significant difference between day 7 vs days 14 and 21 ; ${ }^{a}$ significant decrease of wound diameter in topical silymarin groups ( $10 \%$ and $20 \%)$ vs silver sulfadiazine group. N/A: complete healing. 
Table 2. Histopathological evaluations on burned wounds in the different groups by day 5

\begin{tabular}{lccccc}
\hline Groups & $\begin{array}{c}\text { Ulcera- } \\
\text { tion }\end{array}$ & $\begin{array}{c}\text { Acute inflamma- } \\
\text { tion }\end{array}$ & $\begin{array}{c}\text { Chronic in- } \\
\text { flammation }\end{array}$ & $\begin{array}{c}\text { Crust } \\
\text { formation }\end{array}$ & $\begin{array}{c}\text { Granulation tissue } \\
\text { formation }\end{array}$ \\
\hline 1: Control group & $1+$ & $3+$ & N/A & $3+$ & N/A \\
2: Oral silymarin & $1+$ & $3+$ & $1+$ & $3+$ & N/A \\
3: Silymarin 5\% & $1+$ & $2+$ & $1+$ & $2+$ & N/A \\
4: Silymarin 10\% & $1+$ & $3+$ & $1+$ & $3+$ & N/A \\
5: Silymarin 20\% & $1+$ & $3+$ & $1+$ & $2+$ & N/A \\
6: Silver sulfadiazine & $1+$ & $2+$ & N/A & $2+$ & N/A \\
\hline
\end{tabular}

1+: mild, $2+$ : moderate, $3+$ : severe; N/A: no sign of granulation tissue or chronic inflammation.

Table 3. Histopathological evaluations on burned wounds in the different groups by day 7

\begin{tabular}{|c|c|c|c|c|c|}
\hline Groups & $\begin{array}{l}\text { Ulcera- } \\
\text { tion }\end{array}$ & $\begin{array}{l}\text { Acute inflam- } \\
\text { mation }\end{array}$ & $\begin{array}{l}\text { Chronic in- } \\
\text { flammation }\end{array}$ & $\begin{array}{c}\text { Crust } \\
\text { formation }\end{array}$ & $\begin{array}{c}\text { Granulation tissue } \\
\text { formation }\end{array}$ \\
\hline 1: Control group & $1+$ & $3+$ & + & $2+$ & $2+$ \\
\hline 2: Oral silymarin & $1+$ & $2+$ & $2+$ & $3+$ & $2+$ \\
\hline 3: Silymarin 5\% & $1+$ & $1+$ & $3+$ & $\mathrm{N} / \mathrm{A}$ & $3+$ \\
\hline 4: Silymarin $10 \%$ & $1+$ & $2+$ & $2+$ & $3+$ & $1+$ \\
\hline 5: Silymarin $20 \%$ & $1+$ & $2+$ & $3+$ & $2+$ & $3+$ \\
\hline 6: Silver sulfadiazine & $1+$ & $2+$ & $2+$ & $2+$ & $2+$ \\
\hline
\end{tabular}

1+: mild, $2+$ : moderate, $3+$ : severe; N/A: no sign of crust formation.

Table 4. Histopathological evaluations on burned wounds in the different groups by day 14

\begin{tabular}{|c|c|c|c|c|c|}
\hline Groups & $\begin{array}{l}\text { Ulcera- } \\
\text { tion }\end{array}$ & $\begin{array}{l}\text { Acute inflam- } \\
\text { mation }\end{array}$ & $\begin{array}{l}\text { Chronic in- } \\
\text { flammation }\end{array}$ & $\begin{array}{c}\text { Crust } \\
\text { formation }\end{array}$ & $\begin{array}{l}\text { Granulation tissue } \\
\text { formation }\end{array}$ \\
\hline 1: Control group & $1+$ & $2+$ & $3+$ & $2+$ & $1+$ \\
\hline 2: Oral silymarin & $1+$ & $1+$ & $2+$ & $3+$ & $1+$ \\
\hline 3: Silymarin 5\% & \multirow{3}{*}{\multicolumn{3}{|c|}{$\begin{array}{l}\text { Complete re-epithelisation } \\
\text { Complete re-epithelisation } \\
\text { Complete re-epithelisation }\end{array}$}} & \multicolumn{2}{|c|}{ Chronic fibrosis $2+$} \\
\hline 4: Silymarin $10 \%$ & & & & \multicolumn{2}{|c|}{ Chronic fibrosis $1+$} \\
\hline 5: Silymarin $20 \%$ & & & & \multicolumn{2}{|c|}{ Chronic fibrosis $1+$} \\
\hline 6: Silver sulfadiazine & $1+$ & $2+$ & $2+$ & $2+$ & $2+$ \\
\hline
\end{tabular}

$1+$ : mild, $2+$ : moderate, $3+$ : severe.

wound on day 14 in groups 4 and 5 was 3 mm which was smaller than those in the other groups. On the twenty-first day the skin was completely restored in the fourth group. Also, the average diameter of the wound in the third and fifth group was 1 $\mathrm{mm}$, smaller than in the other groups.

\section{Histopathological findings}

Histopathological evaluations on days 5, 7,14 and 21 showed that the use of $10 \%$ silymarin significantly enhanced the burn wound healing process as compared with silver sulfadiazine, control groups and other silymarin concentrations (Tables 2, $3,4 \& 5$ ). The microscopy of burn wound 
Comparison between the effect of silymarin and silver sulfadiazine on burned wound healing in rats

Table 5. Histopathological evaluations on burned wounds in the different groups by day 21

\begin{tabular}{|c|c|c|c|c|}
\hline Groups & $\begin{array}{cc}\text { Ulcera- } & \text { Acute inflamma- } \\
\text { tion } & \text { tion }\end{array}$ & $\begin{array}{l}\text { Chronic inflam- } \\
\text { mation }\end{array}$ & $\begin{array}{c}\text { Crust } \\
\text { formation }\end{array}$ & $\begin{array}{c}\text { Granulation tissue } \\
\text { formation }\end{array}$ \\
\hline 1: Control group & $\begin{array}{l}\text { Complete re-epithe- } \\
\text { lisation }\end{array}$ & $2+$ & & Fibrosis 3+ \\
\hline 2: Oral silymarin & $\begin{array}{l}\text { Complete re-epithe- } \\
\text { lisation }\end{array}$ & $1+$ & & Fibrosis $2+$ \\
\hline 3: Silymarin $5 \%$ & \multicolumn{2}{|c|}{ Complete re-epithelisation } & & Fibrosis $1+$ \\
\hline 4: Silymarin $10 \%$ & \multicolumn{2}{|c|}{ Complete re-epithelisation } & & $\mathrm{N} / \mathrm{A}$ \\
\hline 5: Silymarin $20 \%$ & \multicolumn{2}{|c|}{ Complete re-epithelisation } & & Fibrosis $1+$ \\
\hline 6: Silver sulfadiazine & $\begin{array}{l}\text { Complete re-epithe- } \\
\text { lisation }\end{array}$ & $1+$ & & Fibrosis $2+$ \\
\hline
\end{tabular}

1+: mild, $2+$ : moderate; $3+$ : severe. N/A: no sign of fibrosis.
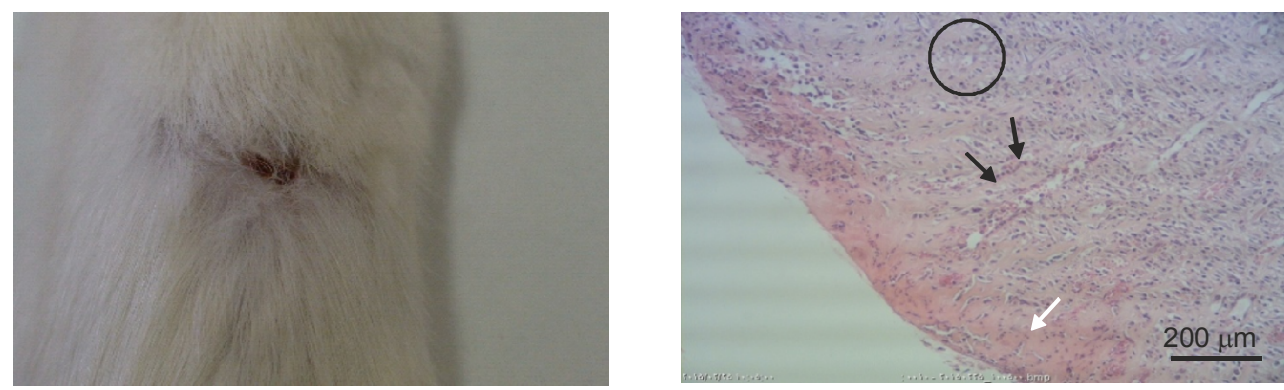

Fig. 1. Macroscopic (left) and microscopic (right) appearance of burned skin in a rat from the control group at day 21 of the experiment. Vascular proliferation (black arrow) is visible; a deposit of collagen matrix is also present (black circle), but there is fibrosis in wound area (white arrow).

healing on days 5 and 7 showed that the changes on the rat skin surface in all groups were the same. On these days the wound surface was covered by a crust consisting of blood coagulum, fibrin, inflammatory cells and debris.

On day 14 there were no significant changes in first, second and sixth groups as compared with days 5 and 7, but some changes were observed like complete reepithelisation, moderate chronic fibrosis (groups 3 and 5), complete re-epithelisation, mild fibrosis (group 4) and complete re-epithelisation.

On day 21 in the control group, the epidermis layer had formed in spite of the fact that some areas showed lack of epidermis in the centre of the wound and numerous mononuclear inflammatory cells were observed around the skin surface (Fig. 1). In the second, third and fifth groups, the epidermis layer was completely formed and moderate and mild chronic inflammation was observed on the surface of skin.

In the sixth group, the epidermis layer was completely formed on day 21 , but the inflammatory cells' content and a moderate number of mononuclear inflammatory cells were seen (Fig. 2). In the fourth group, the epidermis layer was completely formed on day 21, however, the inflammatory cells' content and mononuclear inflammatory cells were not observed on the surface of skin (Fig. 3). 

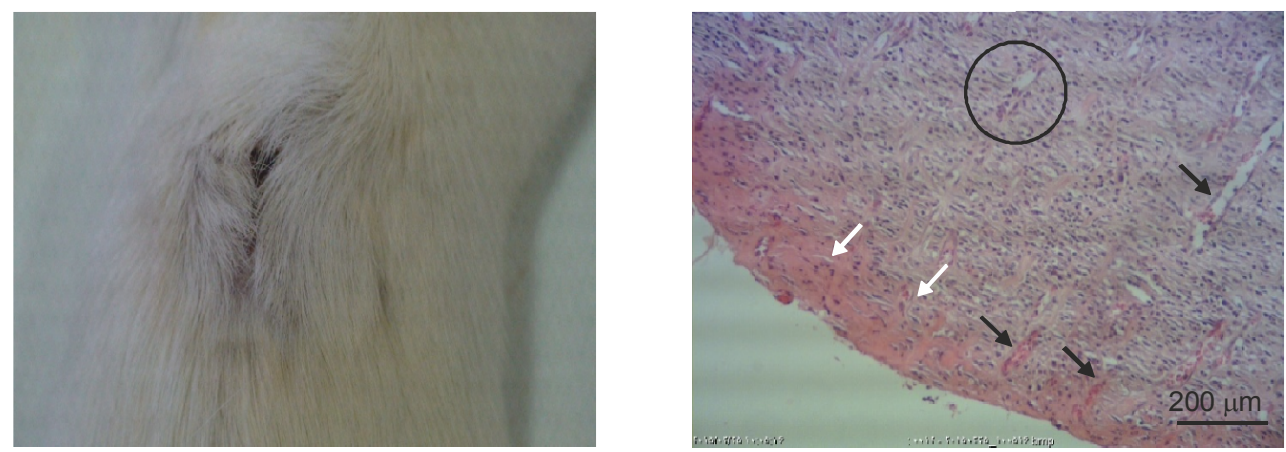

Fig. 2. Macroscopic and microscopic appearance of burned skin in a rat from the sixth group (silver sulfadiazine) at day 21 of the experiment. Vascular proliferation (black arrows), a deposit of collagen matrix (black circle) are visible but there is little evidence of fibrosis (white arrows).
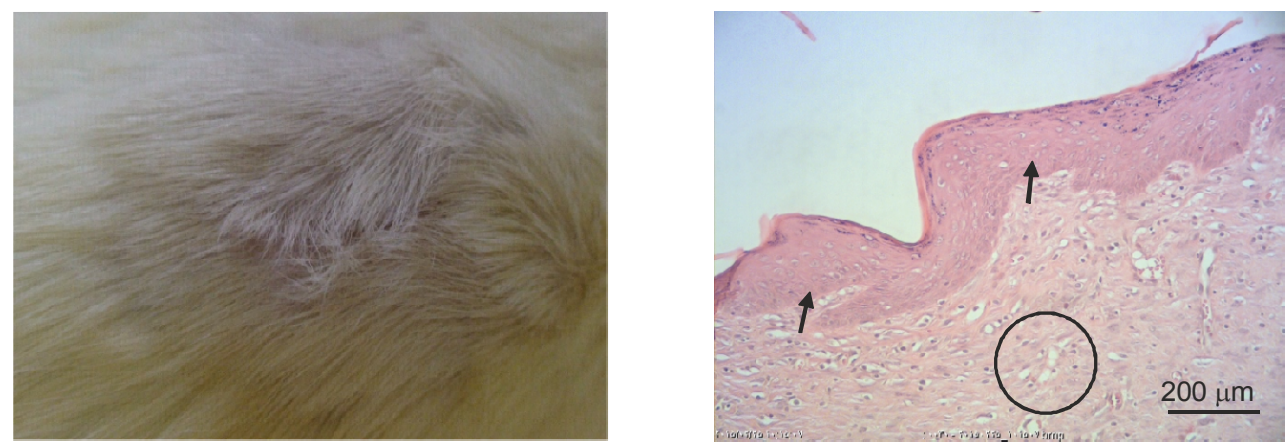

Fig. 3. Macroscopic and microscopic appearance of burned skin in a rat from the fourth group (silymarin $10 \%$ ) at day 21 of the experiment. The black circle indicates collagen arrangement; the epidermis layer was completely formed (black arrows).

\section{DISCUSSION}

Burn wound healing is a complex process in the biological objectives and mechanisms defined by the initial injury. In burn wounds, there is an extensive loss of cells and tissues compared to an incision wound, and this makes the repair process more complicated.

Regulation of inflammation and oxidation are important in the process of burn wound healing (Sharifi et al., 2012). Silymarin possesses anti-inflammatory and anticancer activities (Gu et al., 2007). Many studies have shown that silymarin is able to reduce inflammation in wounds. It has been also shown that silymarin modulates immune response, by augmenting synthesis of anti-inflammatory cytokines, such as IL-10, IL-12 (Chang et al., 2005; Meeran et al., 2006). Early stages of wound healing are associated with acute inflammation, which generates factors that are necessary for tissue repair. On the other hand a prolonged inflammatory phase may cause cell destruction and altered composition of the extracellular matrix leading to failure of epithelisation (Gutiérrez-Fernández et al., 2007). In our study, the effect of silymarin on inflammatory phase may contribute to better wound healing in the silymarin group. 
In addition, antioxidant activity of silymarin has been mentioned by many researchers (Shaker et al, 2010; Anthony et al., 2013), which would help to prevent oxidative damage and promote the healing process. Many studies showed that burn is associated with enhanced generation of reactive oxygen metabolites, which cause lipid peroxidation of the membranes. It is well known that oxygen free radicals can injure lipids, protein, and DNA and thus may contribute to the loss of enzymatic activity or structural integrity. As a free radical generating system, lipid peroxidation is suggested to be closely related with burn-induced tissue damage (Toklu et al., 2007). In the present study the positive effect of silymarin on burn wound healing may be due to its antioxidant activity and prevented burn-induced free radical generation that causes dramatic increases in lipid peroxidation. Silymarin activity was previously demonstrated in vitro by other researchers. For example, it was reported that silymarin acts as a powerful inhibitor against hydrogen peroxide damage in human keratinocytes and mouse fibroblasts (Svobodova et al., 2007). It was also determined that both systemic and local administration of silymarin was effective against burn-induced oxidative damage and morphological alterations in rat skin (Toklu et al., 2006). Recently some researchers outlined that both local and systemic silymarin treatment was effective to reverse the effects of burn induced liver injury (Yemisen et al., 2014).

Collagen fibres treated with the plant flavonoid catechin, have been found to be stable (Madhan et al., 2005). Such stabilisation effect has been shown to involve hydrogen bonding and hydrophobic interactions. Silymarin, a flavonoid from Silybum marianum (L.) Gaertn showed a comparable effect in our histological fin- dings which demonstrated better collagen alignment in silymarin-treated groups.

One of the important issues about silymarin is that it may be accepted as a safe herbal product, since no health hazards or side effects are known in conjunction with the proper administration of designed therapeutic dosages (Solhi et al., 2014). Our results indicated that silymarin had beneficial effects in healing of skin burn wound in rats compared with silver sulfadiazine; this effect may be attributed to its anti-inflammatory effects, antioxidant properties and the effect of silymarin components on collagen fibres. Therefore, silymarin may be useful as a therapeutic agent for the treatment of burn wounds. Nevertheless, more studies should be done to determine the molecular mechanism of silymarin in wound healing.

\section{REFERENCES}

Abramov, Y., B. Golden, M. Sullivan, S. M. Botros, J. J. Miller, A. Alshahrour, R. P. Goldberg \& P. K. Sand, 2007. Histologic characterization of vaginal vs. abdominal surgical wound healing in a rabbit model. Wound Repair and Regeneration, 15, 80 86.

Aliabadi, A., A. Yousefi, A. Mahjoor \& M. Farahmand, 2011. Evaluation of wound healing activity of silymarin (Silybum marianum) in streptozotocin induced experimental diabetes in rats. Journal of Animal and Veterinary Advances, 10, 3287-3292.

Anthony, K. P. \& M. A. Saleh, 2013. Free radical scavenging and antioxidant activities of silymarin components. Antioxidants, 2, 398-407.

Chang, J. W., C. S. Kim, S. B. Kim, S. K. Park, J. S. Park \& S. K. Lee, 2005. Proinflammatory cytokine-induced NF-kappaB activation in human mesangial cells is mediated through intracellular calcium but not ROS: Effects of silymarin. Nephron. 
Experimental Nephrology, 103, e156e165.

Forjuoh, S. N, 2006. Burns in low- and middle-income countries: A review of available literature on descriptive epidemiology. Risk factors, treatment, and prevention. Journal of Burns, 32, 529-537.

Gracia, C. G., 2001. An open study comparing topical silver sulfadiazine and topical silver sulfadiazine-cerium nitrate in the treatment of moderate and severe burns. Journal of Burns, 27, 67-74.

Gregory, R. S., T. Piccolo \& J. P. Hegerres, 2002. Comparison of propolis skin cream to silver sulfadiazine: A naturopathic alternative to antibiotics in treatment of minor burns, The Journal of Alternative \& Complementary Medicine 8, 77-83.

Gu, M., R. P. Singh, S. Dhanalakshmi, C. Agarwal \& R. Agarwal, 2007. Silibinin inhibits inflammatory and angiogenic attributes in photocarcinogenesis in SKH-1 hairless mice. Cancer research, 67, 34833491.

Gutiérrez-Fernández, A., M. Inada, M. Balbín, A. Fueyo, A. S. Pitiot, A. Astudillo, K. Hirose, A. Hirata, S. D. Shapiro, A. Noël, Z. Werb, S. M. Krane, C. López-Otín \& X. S. Puente, 2007. Increased inflammation delays wound healing in mice deficient in collagenase-2 (MMP-8). The Journal of the Federation of American Societies for Experimental Biology, 21, 2580-2591.

Jeschke, M. G., C. Finnerty, O. Suman, G. Kulp, R. Mlcak \& D. Herndon, 2007.The effect of oxandrolone on the endocrinologic, inflammatory, and hypermetabolic responses during the acute phase post burn. Annals of Surgery, 246, 351-360.

Katiyar, S. K., 2002. Treatment of silymarin, a plant flavonoid, prevents ultraviolet lightinduced immune suppression and oxidative stress in mouse skin. Journal of $\mathrm{On}$ cology, 21, 1213-1222.

Madhan, B., V. Subramanian, J. R. Rao, B. U. Nair \& T. Ramasami, 2005. Stabilization of collagen using plant polyphenol: Role of catechin. International Journal of Biological Macromolecules, 37, 47-53.

Meeran, S. M., S. Katiyar, C. A. Elmets \& S. K. Katiyar, 2006. Silymarin inhibits UV radiation-induced immunosuppression through augmentation of interleukin-12 in mice. Molecular Cancer Therapeutics, 5, 16601668.

Mogoşanu, G. D., F. C. Popescu, C. J. Busuioc, H. Pârvănescu \& I. Lascăr, 2012. Natural products locally modulators of the cellular response: Therapeutic perspectives in skin burns. Romanian Journal of Morphology and Embryology, 53, 249-262.

Rupesh, T., J. Nitika, P. Raghvendra \& S. S. Sardul, 2011. Practices in wound healing studies of plants. Evidence-Based Complementary and Alternative Medicine. doi:10.1155/2011/438056.

Sandre, C., D. Agay, V. Ducros, H. Faure, C. Cruz, A. Alonso \& A. M. Roussel, 2006. Kinetic changes of oxidative stress and selenium status in plasma and tissues following burn injury in selenium-deficient and selenium-supplemented rats. Journal of Trauma and Acute Care Surgery, 60, 627634.

Shaker, E., H. Mahmoud \& S. Mnaa, 2010. Silymarin, the antioxidant component and Silybum marianum extracts prevent liver damage. Food and Chemical Toxicology, 48, 803-806.

Sharifi, R., H. Rastegar, M. Kamalinejad, A. R. Dehpour, S. M. Tavangar, M. Paknejad, M. Mehrabani Natanzi, N. Ghannadian, M. Akbari \& P. Pasalar, 2012. Effect of topical application of silymarin (Silybum marianum) on excision wound healing in albino rats. Acta Medica Iranica, 50, 583588.

Solhi, H., R. Ghahremani, A. M.Kazemifar \& Z. H. Yazdi, 2014. Silymarin in treatment of non-alcoholic steatohepatitis: A randomized clinical trial. Caspian Journal of Internal Medicine, 5, 9-12.

Svobodova, A., A. Zdarilova, J. Maliskova, H. Mikulkova \& D. Walterova, 2007. Attenuation of UVA-induced damage to hu- 
Comparison between the effect of silymarin and silver sulfadiazine on burned wound healing in rats

man keratinocytes by silymarin. Journal of Dermatological Science, 46, 21-30.

Toklu, H., T. Akbay, G. Erkanli \& M. Yuksel, 2007. Silymarin, the antioxidant component of Silybum marianum, protects against burn-induced oxidative skin injury. Journal of Burns, 33, 908-916.

Toklu, H. Z., G. Şener, N. Jahovic, B. Uslu, S. Arbak \& B. C. Yeğen, 2006. B-glucan protects against burn-induced oxidative organ damage in rats. International Immunopharmacology, 6, 156-169.

Yemisen, E., A. Tugba, H. Tuklu \& G. Sener, 2014. The effect of silymarin on the liver in thermal burn injury. Marmara Pharmaceutical Journal, 18, 56-61.
Paper received 22.12.2014; accepted for publication 13.03.2015

\section{Correspondence:}

\author{
A. Aliabadi \\ Department of Clinical Studies, \\ School of Veterinary Medicine, Kazerun \\ Branch, Islamic Azad University, \\ Kazerun, Iran \\ e-mail: aaliabadi@gmail.com
}

